\title{
Adversity as Authenticity: How Influencers Use Personal Struggles to BuILD THEIR BRANDS
}

\author{
Adrienne E. Foos
}

Adrienne E. Foos (afoos@sbu.edu) is an Assistant Professor at St. Bonaventure University, School of Business, PO Box BY, St. Bonaventure, NT 14778.

\begin{abstract}
Social media influencers, compared to traditional celebrity endorsers, are perceived as more relatable, and connect with their followers on a personal level. This study explores how social media influencers use their personal struggles to build authentic brand narratives. Using netnography, posts and comments on macroinfluencer Instagram accounts in the female fitness community were observed and analyzed. While not directly paired with sponsored content, expressions of a social media influencers' authentic self, through admissions of personal struggles (e.g. anxiety, eating disorders, psoriasis, cancer, etc.) served as building blocks of their lifestyle and brand systems. By displaying themselves managing or overcoming personal struggles, social media influencers portray
\end{abstract}




\section{The BRC Academy Journal of Business Vol. 11, No. 1}

an aspirational lifestyle that, through emotional engagement, seems more relatable to followers than traditional celebrities.

Keywords: social media influencers, authenticity, branding, Instagram

DOI: https://dx.doi.org/10.15239/j.brcacadjb.2021.11.01.ja05

\section{INTRODUCTION}

\section{Female Fitness Influencers on Instagram}

Social media influencers are popular online opinion leaders with large followings and high social value (Appel, Grewal, Hadi, \& Stephen, 2020). Influencer marketing is an extremely prevalent tactic used by marketers (Hughes, Swaminathan, \& Brooks, 2019), because a single exposure of brands to influencers' core following community can be worth millions of dollars (Appel et al., 2020). This is because social media influencers are perceived as more authentic and trustworthy (Appel et al., 2020), likeable and personal (De Veirman, Caughberghe, \& Hudders, 2017), and credible and relatable (Breves, Liebers, Abt, \& Kunze, 2019) than traditional celebrities by their followers. Social media influencers, once thought to be on the fringe of celebrity endorsements, are now shifting our notion of what it means to be a celebrity. With the rise of influencers, there are no fixed rules defining them. Considering that average follower counts increase over time, micro-influencers tend to have approximately 5,000-75,000 followers and macro-influencers tend to have approximately 75,000-3,000,000 followers on Instagram. Some 'InstaFamous' fitness influencers, such as Kayla Itsines and Jen Selter (both with 12,600,000 followers) have become celebrities in their own right. On Instagram, the female fitness community is a large and active subculture (hashtags with the word 'fit' generate hundreds of millions of posts) with prominent influencers, and many associated brands (e.g. brands related to supplements, fitness programs, fitness apparel, equipment, and 
cosmetics, etc.). This provides a rich context in which to examine how influencers construct authenticity and brand identity.

Influencers move from a general social media user to an influencer when they are identified by companies as having a significant following within their target market, as well as compatible messaging (Breves et al., 2019). For example, an Instagram user with 217,000 followers who posts workout routines wearing Gymshark leggings (@libbychristensen) was tapped by Gymshark to be a brand ambassador for their fitness apparel. There are different levels of partnerships influencers can have with businesses. The least involved are sponsored posts. With sponsored posts, companies offer a flat rate per post featuring the product or service. Similarly, influencers may have their own discount codes. In this case, influencers promote the use of their discount codes (e.g. WHITNEY10) when purchasing a product they endorse so they can receive a commission on the sale. Brand ambassadorships tend to be long-term partnerships between influencers and brands. The terms of the relationship vary, but brand ambassadors usually have contracts for number of sponsored posts, receive free products, and command higher sums per post. If an influencer is particularly popular, they may collaborate with a brand to produce their own line of products. For example, fitness influencer Whitney Simmons has worked with tarte Cosmetics, TULA Skincare, and Gymshark to launch her own collaborations. Finally, the end goal for most full-time influencers is to create their own companies. For example, Taylor Chamberlain-Dilk, after years working as a brand ambassador, started her own athletic apparel company, Balance Athletica.

This paper delves into the world of a select few female fitness influencers on Instagram whose source of authenticity is their sharing of personal struggles they have overcome to become fit, healthy, and successful. Using the case study approach to netnography, it examines the cultural branding and emotional connection influencers co-construct with their followers via shared experiences, personal interaction, private life vignettes, and brand recommendations. I find that the personal struggle 


\section{The BRC Academy Journal of Business Vol. 11, No. 1}

narratives build authenticity, influencers carefully project aspirational yet accessible lifestyles, and brand values are co-created through personal interaction between influencers and followers. Finally, the paradoxes of the female fitness influencer subculture are extrapolated.

\section{LITERATURE REVIEW}

\section{Authenticity}

The context of female fitness influencers, and their relationships with brands and their communities is highly symbolic, highlighting the importance of studying the role of authenticity in these relationships, because "authenticity concerns issues of symbolism and meaning" (Beverland, Lindgreen, \& Vink, 2008, p. 6). Consumers seeking meaning in their lives confer authenticity to people and brands (Beverland \& Farelly, 2010). The "search for authenticity is one of the cornerstones of contemporary marketing” (Brown, Kozinets, \& Sherry, 2003, p. 21), however, it is difficult to define (Beverland \& Farelly, 2010) and little is understood (Beverland, Lindgreen, \& Vink, 2008). Authenticity imbues products with a set of differentiating values (Beverland, Lindgreen, \& Vink, 2008) and original brand essence (Brown, Kozinets, \& Sherry, 2003). Authenticity does not need to square with reality. It is the perception of authenticity from which consumers derive meaning from their experiences. According to Belk and Costa, authenticity is a negotiated, constructed, and romanticized alternative reality (1998). In the world of Instagram, influencers carefully construct an alternative reality reflecting their values. Of the different types of authenticity categorized by Beverland, Lindgreen, and Vink, fitness influencers' mode of authenticity fits best in the 'moral' category (2008). Moral authenticity "provide(s) (the) consumer with a feeling that this brand will help achieve self-authentication through connecting with personal moral values (Beverland, Lindgreen, \& Vink, 2008, p. 8). The self-focused nature of social media offers a way for influencers to express their moral authenticity. In narrating their journey from struggling to healthy, love for fitness, and trial of different related products, influencers 
define their brand identity, connect to their community, and gain moral credibility (Gannon \& Prothero 2016). Authenticating acts are "selfreferential behaviors that reveal or produce the true self" (Arnoud \& Price, 2000, p. 8). Demonstrating the use of a product in this context, then, is an authenticating act. Members of fitness communities on Instagram consume products and content from brands and influencers they perceive as authentic to help reinforce their desired self-identity (Beverland \& Farelly, 2010).

To enhance self-identity, consumers have different goals. Some consumers find meaning in seeking mastery, connection with likeminded others, or by nurturing pure values (Beverland \& Farelly, 2010). Finding these values reflected in their favorite influencers helps cultivate engagement. To confer authenticity to achieve identity goals, consumers negotiate meaning using a broad range of brand cues (Beverland \& Farelly, 2010). To reinforce their sense of self, consumers focus on cues that demonstrate purposeful efforts to construct authenticity (Beverland \& Farelly, 2010). It is likely that sharing the journey to overcome a personal struggle with followers, which may be perceived as revealing the true self, demonstrates an effortful attempt to establish authenticity on the part of the influencer, because imperfections are seen as antithetical to the glossy and photoshopped world of professional fitness models (Shoenberger, Kim, \& Johnson, 2020). By signaling their authenticity through sharing their personal struggles, influencers provide followers a beacon for achieving their desired goals for self-identity. Followers actively construct authenticity around influencers they deem genuine by mimicking the influencer's consumption habits.

\section{Cultural Branding}

Meaningful brand identity, like authenticity, is socially constructed and co-created with followers, influencers, and other cultural intermediaries (Preece, 2015). In performing values related to brand identity, influencers negotiate authenticity (Preece, 2015). In other words, if influencers genuinely perform authenticity, and that authenticity is conferred upon 


\section{The BRC Academy Journal of Business Vol. 11, No. 1}

the brands they endorse by their followers. Influencers and followers cultivate the self through brands with congruent brand identities (Holt, 2002). Influencers and followers not only cultivate the self through brands, but also symbolically express their collective selves by integrating brands in their lifestyles (Holt, 1997). In the female fitness community on Instagram, this would be evidenced by followers mimicking the lifestyles of their favorite influencers.

Influencers can use cultural mythmaking as a means for creating a compelling narrative and advancing their consumption agenda (Thompson, 2004). Female fitness influencers have many archetypes for which they can embody. For example, they may choose to build an underdog mythos, in which they overcome adversity to achieve fitness and lifestyle goals. This mythos would feed into their perceived authenticity. Influencer myths of transformation provide symbolic resources for negotiating identity around belonging and authenticity (Kerrigan et al., 2011). Authenticity is staged by influencers through media and used as a mode of production to meet marketing ends (Kerrigan et al. 2011). In brand-related advertising, tactics used to stage authenticity often involve calling attention to unique imperfections and downplaying attributes that might garner mass appeal (Beverland, Lindgreen, \& Vink, 2008). For otherwise conventional fitness influencers hoping to reinforce their authenticity, they may regularly discuss a unique personal struggle to differentiate themselves from other fitness influencers. In other words, common people experiencing an uncommon situation, and observing them as they navigate that situation builds authenticity (Rose \& Wood, 2005). Authenticity is also staged through authentic engagement with followers (Preece, 2015).

\section{Social Media Context}

The social media context reinforces the relationship between influencers, brands, and followers. On Instagram, influencers construct their own world and curate the aesthetic and values they share with their followers. Professional influencers are consistent with the aesthetic and 
values they share, which essentially commodifies their lifestyles as a brand identity. An essential part of the authenticity co-creation process between influencers and their followers is the perceived public display of private life by influencers on social media (Preece, 2015). Influencers curate vignettes of their private lives for their followers to consume. This makes followers feel more closely connected to influencers than traditional celebrities. By inviting followers into their private lives, influencers gain trust and are viewed as experts by their followers (Appel et al., 2020). There is a sense of voyeurism on the part of the follower and theater on the part of the influencer (Rose \& Wood, 2005). By showing everyday aspects of their lives or sharing personal struggles, influencers provide an illusion of transparency and normalcy that further strengthens the perceived connection between influencers and followers (Preece, 2015). Imagery on Instagram of influencers in everyday situations, staged strategically to express authenticity, is perceived as sincere by followers (Gannon \& Prothero, 2016). The particular context of drawing attention to bodily imperfections in photographs is linked to perceived realness, because consumers feel solidarity with the body-positive movement (Shoenberger, Kim, \& Johnson, 2020).

Social media encourages the direct interaction between influencers and followers. By interacting directly with their followers, influencers seem more 'real' and authentic (Preece, 2015). The immediacy of interaction and perceived accessibility of influencers' lifestyles feeds engagement and emotional investment in influencers by followers. This engagement and emotional investment is transferred to brands influencers weave into their narratives, because first person narratives are considered more personal (Appel et al., 2020), and credible (De Veirman, Cauberghe, \& Hudders, 2017). In this sense, "influencer marketing has been described as a type of native advertising, branded entertainment, or highly credible electronic word of mouth" (Breves et al., 2019, p. 441). 


\section{The BRC Academy Journal of Business Vol. 11, No. 1}

\section{METHOD}

A case study approach to netnography (Kavakci \& Kraeplin, 2017) was used to study female fitness influencers on Instagram. The purpose was to understand their use of highlighting personal struggles to construct authenticity and brand identity. According to Kozinets, "netnography is a form of qualitative research that seeks to understand the cultural experiences reflected in ... systems of social media" (2020, p. 14). The case study approach allowed me to deeply immerse myself in the small worlds co-constructed by female fitness influencers and their followers. Netnography provides a set of techniques for collecting and interpreting cultural data on social media. Instagram influencers are an ideal sample for netnography, because Instagram makes it easy for influencers to commoditize their narratives in the hopes of gaining brand ambassadorships (Kozinets, 2020). The richness of the social systems built between influencers, followers, and brands, mediated by Instagram's platform, provide fertile ground to study. The world of Instagram fitness influencers is large, as stated earlier, Jen Selter and Kayla Itsines have some 12.6 million followers each. There are many subcultures within the world of Instagram fitness influencers, from those focused on professional bodybuilding to vegan fitness, etc. I sought to identify a set of female fitness influencers who explicitly weaved their personal struggles into their brand narratives on Instagram. Unfortunately, eating and related disorders are common in the fitness world. While discussing overcoming an eating disorder may make fitness influencers more relatable, the ubiquity of overcoming an eating disorder, alone, is not often inspiring enough for people to follow their journey. Therefore, to narrow the scope of data collection, I looked for personal struggles in addition to probable eating and related disorders that serve as differentiators in the eyes of their followers. Furthermore, the influencers needed to have a significant following, number and consistency of posts, and brand ambassadorships to warrant inclusion. This level of social significance was important both to provide enough data and to ensure the influencers were truly public 
figures, given the sensitivity of some of the subject matter. The identities of followers are obscured, since they are not public figures.

Four influencers met these criteria: Whitney Simmons, an American fitness influencer with psoriasis, Taylor Chamberlain-Dilk, an American fitness influencer with anxiety, Linn Lowes, a Swedish fitness influencer who overcame cancer, and Lauren Simpson, an Australian fitness influencer who overcame childhood cancer and recently underwent bowel surgery. All of their Instagram posts and comments available by May 2020 were collected. Influencers tend to heavily edit and delete old posts to curate their 'aesthetic', so posts were observed for over 2 years. Their YouTube channels and websites were also visited to gather background information. Overall, the influencers were similar demographically. They were all blond, white, thin, privileged, heterosexual, in their 20s and early 30s, partnered with fit, white men. They also all own small dogs and prefer modern interior design. The goal was to understand how the influencers weave their personal struggles and brand identity into their narratives, and how they connect with their followers to co-create authenticity. Specifically, I looked into each influencer's professional background, their brand relationships, framing of their personal struggles, types of typical posts, reactions of their followers to different types of posts, interaction with followers, and meaningful language, imagery, and themes that arose. Taken together, I hoped to comprise influencers' use of personal struggles to build brand identity and authenticity through emotional connections with followers.

\section{Whitney Simmons}

Whitney Simmons is a 27-year-old American fitness influencer. As of May 2020, Whitney Simmons had 3 million followers and 926 total posts. She was a high school athlete and a college cheerleader, until she was cut from the team. She cites this low point as an inspiration for her to build a healthier lifestyle. She is not a licensed personal trainer or nutritionist. Simmons typically posts workout routines, but also includes posts about beauty, travel, her dogs, her fiancé, interior design, fashion, 
and food. She espouses a 'positive vibes' lifestyle, starting each Instagram story with her catchphrase "it's a beautiful day to be alive". Simmons designed and sponsored her own lines for Gymshark fitness apparel, tarte cosmetics, and Tula skincare. She is a brand ambassador for Gymshark and Alani nu supplements, and has discount codes in her name for various smaller brands. She owns a fitness app called Alive, where users can follow workout routines and track their progress (https:// whitneyysimmons.com/, n.d.).

Whitney Simmons has psoriasis, an autoimmune disease causing red patches (plaques) on the skin (https://www.cdc.gov/psoriasis/index.htm, n.d.). Simmons rarely dedicates posts to psoriasis, although her psoriasis plaques are sometimes visible in other posts. In a psoriasis-related post, Simmons photographed herself in her underwear showing visible plaques on her arms, legs, and stomach. An excerpt of the caption reads:

Flaws are what makes us human. So whether you have stretch marks, psoriasis, cellulite, eczema, etc... embrace it. My psoriasis no longer upsets me like it used it [sic]. I hardly notice them anymore because they're now apart of me and my body. MY BODY!! This amazing machine that hold us up and allows us to walk, talk and breath [sic]... and that's what I'm grateful for today. It's a beautiful day to be alive. (Simmons, 2020)

Her psoriasis-focused posts average 7,000 comments and 264,000 likes. For reference, her typical posts average 700-2,000 comments and 100,000 likes. Giveaway posts (averaging approximately 61,000 comments and 183,000 likes) and launch announcement posts (averaging approximately 8,000 comments and 186,000 likes) receive the most engagement. When her plaques are visible in her typical posts, she often receives comments about psoriasis. For example, in a post featuring an encouraging and positive caption in which Simmons wears a bikini with visible plaques, shows and example of a comment on psoriasis on a post of Simmons in a bikini with visible plaques a comment reads, "I have psoriasis and looking at your pics makes me more confident and not so self conscious! 
Thank you" (Simmons, 2019). The follower not only relates to Simmons' post, but also feels empowered. Another follower comments asking about the brand of the bikini, showing the convergence of branding, emotional connection to influencers, and influencers' self-promotion using personal struggles.

\section{Taylor Chamberlain-Dilk}

Taylor Chamberlain-Dilk is a 27-year-old American fitness influencer. As of May 2020, Chamberlain-Dilk had 772,000 followers and 2,499 total posts. Chamberlain-Dilk has a bachelor's degree in dietetics and is a (retired) professional body builder. Chamberlain-Dilk typically posts workout routines, fashion, food, beauty, her friends and family, her husband, spirituality and wellness, her dogs, and travel. She advocates a balanced lifestyle, showing a mixture of fitness and posed photoshoot posts with drinking, eating out, and beauty treatment posts. Chamberlain-Dilk is the Chief Executive Officer of Balance Athletica, a fitness apparel company she started with her husband and sister (https://www.balanceathletica.com/pages/about-our-mission, n.d.). Before launching her own fitness apparel company, she was a Gymshark ambassador. She used to sell training programs and was a $1^{\text {st }}$ Phorm supplement ambassador; however, she has since stepped back from her brand ambassadorships to focus on her business. Chamberlain-Dilk now recruits and develops "leaders" for Balance Athletica; her own brand ambassadors.

Taylor Chamberlain-Dilk frequently discusses her struggles with anxiety, acne, and the eating disorder she overcame. She often discusses the journey to lead a balanced lifestyle as the solution for her mental health issues. In a November 1, 2019 post, Chamberlain-Dilk explains:

There was a time not too long ago where i [sic] felt numb. I didn't want to get out of bed, i [sic] had no motivation keep building my dreams, and laughter felt forced. One day i [sic] decided i [sic] needed a change. I quit competing in bikini competitions, started a new business venture (@balanceathletica), and moved back to 
where I'm from (Colorado. I'd had enough of living my life each day waiting for the day to be over. The decisions i [sic] made and stuck to, have drastically changed my world. For the better. I wake up excited to start the day and to be alive...

Her struggle-focused posts average 300 comments and 20,000 likes. For reference, her typical posts average 400 comments and 23,000 likes. Giveaway posts (averaging approximately 8,500 comments and 32,000 likes) receive the most engagement. In eating disorder recovery post displaying side-by-side bikini pictures of Chamberlain-Dilk emaciated, in competition form, and then at her current weight, a follower commented, "it's nice to know that someone else has had the same experience and that you have found your balance" (Chamberlain-Dilk, 2018). The follower is relating to Chamberlain-Dilk's journey and affirming Chamberlain-Dilk's assertion that finding balance is the answer. In an August 4, 2019 post, Chamberlain-Dilk strikes a pose with her face still red and swollen from a microneedling treatment for her acne. This post is a more overt attempt to build perceived authenticity, by showing followers the 'real Taylor'. A follower comments that Chamberlain-Dilk is "brave" and that "the outer shell does not define us". This follower also relates the shared experience. The next two comments remark on her outer beauty.

\section{Linn Lowes}

Linn Lowes is a 31-year-old Swedish fitness influencer. As of May 2020, Lowes had 2.4 million followers and 2,977 total posts. Lowes is a licensed personal trainer and works out exclusively in her fully equipped home gym built for filming and posting on Instagram. Lowes typically posts workout routines, before and after photos of her clients, her home, fiancé, dogs, fashion, and travel. She takes a fun, lighthearted approach to fitness, often poking fun at her 'fails', using silly emoji's, and sticking out her tongue. Lowes has both fitness and meal plan apps, and is developing fitness apparel and self-tanner companies. She had previous partnerships with other fitness apparel and fashion brands, but now focuses on promoting her own businesses. 
Linn Lowes frequently discusses overcoming lymphoma in her mid-20s, as well as a probable eating disorder (she does not definitively say she had an eating disorder, but frequently mentions undereating and over-exercising, and posts pictures of her own before-and-afters). When posting her underweight before pictures beside her more muscular after pictures, Lowes highlights the importance of consistency in reaching one's goals, and that the journey to reaching those goals is not a straight line. She credits the struggles she went through battling cancer as a source of motivation for being healthy, rather than focusing solely on aesthetic ideals. In a post from April 4, 2020, Lowes celebrates 6 years of being cancer free. Lowes' cancer posts receive an average of about 326,000 likes, but about the same number of comments as her typical posts (650 comments, 85,000 likes). The next fitness influencer discussed, Lauren Simpson, comments on the post that Lowes is an inspiration. Before-and-after posts average about 1 million likes (again, with the same 650 comment average). While one follower hailed Lowes as a motivator, another brought up her self-tanner brand in development. This again shows the melding of personal struggles and brand identity in influencers' narratives on Instagram. In a February 1, 2020 post, Lowes is posed walking away from the camera in a red bikini displaying what most would consider an exemplar of the Western ideal of beauty. She uses the post, however, to point out her flaws, such as barely visible cellulite and touching thighs, saying: " $i$ [sic] train 5-6 times per week and I've done so for years, my nutrition is good, I still have cellulite, my thighs touches [sic], I get pimples and I bloat like crazy at some times - it's called, being human". Lowes urges followers to accept themselves as imperfect human beings. From an outside view, this can be construed as disingenuous; however, followers perceive it as the opposite. For example, Lowes posted a photo of herself and her fiancé, which is heavily staged and edited (the trees in the background of the image are distorted), and a follower comments on Lowes' genuineness: "Idk you but you seem genuine and are one of the very few fitness people I follow" (Lowes, 2019). It seems followers take slight mentions of imperfection in personal 


\section{The BRC Academy Journal of Business Vol. 11, No. 1}

life vignettes as evidence for authenticity. Lowes' struggle-related posts receive the most likes compared to her typical workout posts; however, her giveaway posts receive the most comments (approximately 3,000).

\section{Lauren Simpson}

Lauren Simpson is a 28-year-old Australian fitness influencer. As of May 2020, Simpson had 1.8 million followers and 3,375 total posts. Simpson is a world champion professional body builder. Simpson typically posts workout routines, food, her boyfriend, pets, beauty, nights out with friends, and fashion. She preaches body acceptance, confidence, consistency, and living life without guilt. She alternates between a coach-style tone when talking about exercises and nutrition, posed photoshoots with motivational quotes, before and afters of herself and clients to promote her programs, and more personal posts of her everyday life. Simpson's primary business is selling eight-week online fitness programs. She also sells workout equipment, and nutrition e-books. Simpson collaborates with Ryderwear fitness apparel to design her own lines, as well as Worldwide Lashes for her own fake eyelash style. She is a brand ambassador for EHPlabs supplements, Blessed protein powder, Lust protein bars, and FitCover cosmetics. Simpson promotes all of the clothing she wears and beauty treatments she receives (such as hair extensions, hair care products, etc.) by linking to their Instagram accounts, however, she does not receive compensation for these posts.

Lauren Simpson frequently discusses her struggles with accepting her scars from childhood kidney cancer and emergency bowel surgery, as well as a probable eating disorder. Given her line of work, the scars on her stomach are almost always visible in each post and she almost always receives comments on them, whether or not the post specifically focused on her scars. She explains that consistent strength training and nutrition gives her the confidence to show off her body. For example, on May 31, 2020, Simpson posted a picture of herself in a bikini with her scar visible, captioning that every woman deserves to feel confident and that her scars are a source of strength. Taylor Chamberlain-Dilk liked the post. 
Her bowel surgery posts receive the most comments (approximately 2,000 ) and likes (approximately 488,000) compared to her typical posts (averaging about 500 comments and 30,000 likes). In a February 16, 2020 post, Simpson showed a side-by-side photo of herself bikini-clad at a photoshoot in the morning and with a bloated stomach at night. One follower comments: "Thanx [sic] for posting this, makes the rest of us feel normal". The next comment says: "Social Media needs more real posts like this...Thank you for showing everyone this truth...you are a prime example of keeping others hopeful on their journeys and keeping people in check of the fact that we are all friken human!". These comments demonstrate that followers perceive Simpson as 'real' and 'human' by posting herself suffering from a common inconvenience many women experience. Admitting to sharing this common struggle with others builds authenticity, despite the bloating photo being alongside a highly glamorous, posed photo from a photoshoot (not a common experience amongst most women). In the same format as Chamberlain-Dilk (three photos shown side-by-side of Simpson underweight, in competition form, then her current physique), Simpson uses her own body transformation as part of the narrative about her journey from undereating, over exercising, and feeling insecure, to bodybuilding, focusing on nutrition, and feeling confident (Simpson, 2020). A follower again comments on how honest and real Simpson is, and then mentions that she plans to purchase an 8 -week challenge program. The personal struggles, authenticity, and branding again converge for an influencer.

\section{FindingS}

\section{Personal Struggles}

How influencers frame their personal struggles builds the identity they want to convey. Influencers framed their personal struggles as part of their origin story for transformation. They refer to the gym as their 'savior' during crises. They see the outer transformation of their bodies (e.g. from weak to strong or unhealthy to healthy) as a reflection of 
their inner change (e.g. insecure to confident or anxious to calm). In doing so, influencers see fitness and nutrition as a solution for not only physical ailments, but also mental health and even social justice issues. When influencers post about their struggles, followers present their own struggles in the comments. By sharing the experience, followers feel part of the transformation and co-construct a communal identity. Comments such as 'if you can do this so can I', or even providing advice and motivation to the influencer ('you got this!'), appeared in some form regularly in the comments sections. As influencers gain followers, they use their struggle origin story as a basis for wading into Zeitgeist flashpoints, such as promoting body positivity, female empowerment, and inclusivity, as part of their values and identity. Whitney Simmons, Linn Lowes, and Lauren Simpson all caption posts of themselves with motivational, body positive/female empowerment quotes, while Taylor Chamberlain-Dilk focuses on inclusivity by using diverse and plus-sized models. These actions speak to followers, who comment using terms such as brave, fighter, inspiration, strong, and powerful.

Whitney Simmons, Lauren Simpson, and Taylor Chamberlain-Dilk all discuss the pressure on influencers to be 'always on' on social media (Linn Lowes presents the most performative identity of the four). They use the exposure of their private selves to rebel against this pressure. In between photos from professional photoshoots, workout routines, or advertisements, they stage glimpses into the real them- by being silly, eating treats, or sitting at home on the couch, for example. Whitney Simmons and Taylor Chamberlain-Dilk also take days where they 'detox' from social media by not posting for a day. Simmons, Simpson, and Chamberlain-Dilk give their followers access to their everyday life in the form of 'full day of eating' posts, or FDOE, posts influencers cite as the most frequently requested by their followers. FDOE posts consist of the influencers recording and posting every meal they consume throughout a day. They further make their private selves by posting beauty routines, such as makeup or hair styling tutorials. Followers feel as though they are getting a behind-the-scenes look into the influencers' daily lives. 
They comment with words such as relatable, human, genuine, and real. Despite the fact that most of the influencers lack formal training in nutrition and kinesiology, overcoming their struggles and sharing their tactics for doing so enhances their perceived credibility (Xiao, Wang, \& Chan-Olmsted, 2018). That they are brave enough to share their private struggles publicly enhances their perceived authenticity.

\section{Aspirational Lifestyles}

When influencers curate their lifestyle vignettes, they use a strikingly similar aesthetic- bright lighting, white and pastel clothing and backgrounds, modern interior designs, and a cheerful tone. All of the influencers use their partners and dogs as props in their photoshoots. Though the influencers likely earn more money than their partners do, they tend to conform to traditional gender roles and feminine ideals. While rarely seen or mentioned, all of the influencers employ full support teams of marketers, photographers, chefs/food stylists, social media content managers, editors, and personal assistants to build a seemingly accessible, but aspirational lifestyle. The influencers credit consistent routines, self-care, journaling, and practicing gratitude as helping them achieve their goals and overcome their struggles. These solutions usually involve consumption, for example, Chamberlain-Dilk's company developed a calendar with journaling and self-care components that they sell. When the influencers post aspirational photos, they use terms such as authentic, inclusive, balanced, well-being, uplifting, inspire, and motivate. Followers comment on aspirational posts using terms such as goddess, perfection, and goals. There is a disconnect between the highly stylized and staged images influencers post highlighting their successful lifestyles and the captions they write preaching authenticity, however, followers do not perceive this as a paradox. Instead, followers see influencers as aspirational members of their own community.

\section{Brand Systems}

The authenticity co-created by influencers and their followers transmits authenticity to the brands influencers endorse (Fujita, Harrigan, \& Soutar, 
2019). When influencers have brand ambassadorships or their own brands/lines, they trial and review new products for their followers. The authenticity built by influencers makes these reviews more trustworthy for followers. The brand becomes a symbol of overcoming or accepting the struggle. Followers then begin to co-create brand values. They buy products endorsed by their favorite influencers and post photos of themselves with those products to be part of the community. Influencers interact with followers using their endorsed brands informally. For example, Lauren Simpson often refers to followers using 'hun' or 'babe'. They may act in a customer service role. Taylor Chamberlain-Dilk meticulously details every design aspect of her fitness apparel before collections launch, and answers followers' questions regarding sizing, material, and color of each piece of clothing. In turn, influencers amplify their followers by re-posting followers using endorsed products or beforeand-after body transformations.

Comments and likes from followers further legitimize brand claims. Even when posts are not brand-focused, followers comment asking about brands consumed in the photos. For example, on a post by Whitney Simmons announcing a giveaway for student scholarships sponsored by a supplement company, she received numerous comments asking for the brand of her boots. Followers even ask about the wallpaper she has in her bedroom. Success in brand ambassadorships lends influencers credibility in starting their own companies, often in direct competition to their previously supported brands. As the influencers grow in followers, they tend to transform beyond their fitness identities (e.g. by creating fitness-only second Instagram accounts, removing the @name_fit from their handles and changing it to their full names, or by retiring from professional bodybuilding). In conjunction with shifting their Instagram identities, influencers move to endorsing or launching fitness-adjacent brands, such as supplements, apparel, equipment, cosmetics, or skincare, etc. The influencers struggle to move too far beyond their area of fitness expertise. 


\section{Conclusion}

In interpreting the data, many paradoxes were evident; however, they did not seem to concern followers. Consumers have been found to relish in the ironic mixture of the real and staged in the similar context of reality television, finding it no less authentic (Rose \& Wood, 2005). The mixture of real and staged moments on Instagram may provide followers with the simulated experience of reality. There was a tension between authenticity and aspiration- a difficult line for influencers to walk. They use personal struggles and glimpses into their private lives to build authenticity, while also including highly stylized, professional photos staged by their support teams. Followers perceive the lifestyle influencers portray on Instagram as aspirational, yet accessible- if they consume the same brands and follow the same routines as the influencer, they too can reach their goals. Another paradox is body acceptance versus conformity. All of the influencers fit well within Western feminine ideals of beauty, however, they preach body acceptance to their followers. Their hyper-focus on fitness, nutrition, and beauty seems to belie their captions to accept one's flaws as-is. Finally, followers felt powerful, emotional connections to influencers, due to their perceived authenticity. The hedonic content of posts increases engagement with influencers (Hughes, Swaminathan, \& Brooks, 2019). However, influencers careful manage their impressions by curating vignettes of their lives. Authenticity is, therefore, an iterative process as influencers edit or delete old posts to fit their current message and aesthetic, and by carefully constructing future content. In doing so, influencers have shifted the meaning of celebrity by commoditizing their private life and sharing their branded selves.

The subculture of female fitness influencers and followers on Instagram is its own community, with influencers commenting and collaboration with one another, and followers mimicking influencers in their consumption, poses, and speech patterns. Followers symbolically consume what the influencer consumes to aspire to achieve their success. This is evident in 'lookalike' posts, in which followers post similar images and 
motivational quotes to their favorite influencer. A follower of Taylor Chamberlain-Dilk and aspiring fitness influencer, for example, tagged Chamberlain-Dilk in a post offering advice for how to reduce anxiety (one of Chamberlain-Dilk's personal struggles). In the post, the follower wears Balance Athletica clothing and even holds the same breed and color of dog as the ones Chamberlain-Dilk owns. Chamberlain-Dilk liked the post. Followers self-identify as members of the group by consuming endorsed brands to confer the exemplary values of the community to themselves, which in turn reinforces the brand identity (Fujita, Harrigan, \& Soutar, 2019). This level of interaction further shifts our notion of celebrity. Followers moderate comments sections by defending influencers against negative commenters or misogynists. Followers feel as though influencers are speaking directly to them. For example, followers comment 'I'm struggling and I needed to hear this' on motivational posts. Influencers even encourage followers to help them build content by polling followers on what types of posts they would like to see. For example, Linn Lowes asks followers what types of exercises they would like her to demonstrate (e.g. 'glutes or abs?'). This gives followers actual power over the content from influencers they consume- fed by the co-created values rooted in overcoming authentic struggles to achieve an aspirational lifestyle.

Taken together, the findings suggest authenticity is negotiated through the personal struggle narratives influencers share and the emotional interaction of followers. Authenticity is transmitted from influencers to the brands they endorse, and followers' co-create their group identities and the values of the brands by posting their consumption lifestyles to the community. Overall, this is just an in-depth look into several cases of female fitness influencers who share personal struggles with their followers on Instagram.

\section{Limitations AND FUtURE RESEARCH}

Although this study provides important insights into the topic of authenticity and social media influencers, some limitations and suggestions 
for future research need to be acknowledged. First, this study examined a small influencer subculture within the online fitness world. Further research could explore other influencer subcultures dealing in authenticity paradoxes and brand identity, such as fashion or music.

Second, I observed a homogenous group of female influencers on one social media platform. Future studies could expand to a more diverse group of individuals on different platforms. Tik Tok and other videobased platforms will provide a rich context for studying themes explored in this paper.

Third, this study focused on sharing personal struggles as authenticating acts, however, studying sharing systemic struggles as an authenticating act may yield interesting insights. It may be meaningful to examine how navigating racism, sexism, homophobia, or fat-shaming, for example, serve as authenticating acts for fitness influencers.

Finally, I only explored personal struggles as authenticating acts using a limited sample. Future research can compare more factors influencing levels perceived authenticity from a quantitative perspective using experiments. It will be interesting to see how different images are perceived by a larger sample.

In conducting this research, it became apparent that there comes a point when a social media influencer gains a large enough following, that they become akin to a traditional celebrity. It would be interesting to explore the perceived authenticity of 'Insta-Famous' influencers, as they become more distant from the experiences of everyday consumers. Furthermore, virtual influencers (human-like CGI influencers) have been identified as an important avenue of marketing research (Appel, et al., 2020), for which the study of imperfections as a path to authenticity is particularly relevant. 
142 The BRC Academy Journal of Business Vol. 11, No. 1

\section{REFERENCES}

About our mission. (n.d.) Balance Athletica. Retrieved April 30, 2020 from https://www.balanceathletica.com/pages/about-our-mission.

Appel, G., Grewal, L., Hadi, R., \& Stephen, A.T. (2020). The future of social media in marketing. Journal of the Academy of Marketing Science, 48, 79-95.

Arnould, E.J. \& Price, L.L. (2000). Authenticating acts and authoritative performances: questing for self and community. In Ratneshwar, S., Mick, D.G., \& Huffman, C. (Eds.), The why of consumption: contemporary perspectives on consumer motives, goals, and desires (pp. 140-163). Routledge.

Belk, R.W., \& Costa, J.A. (1998). The mountain man myth: a contemporary consuming fantasy. Fournal of Consumer Research, 25(December), 2218-240. https://doi.org/10.1086/209536

Beverland, M.B., \& Farrelly, F.A. (2010). The quest for authenticity in consumption: consumers' purposive choice of authentic cues to shape experienced outcomes. Journal of Consumer Research, 36(February), 838-856.

Beverland, M.B., Lindgreen, A., \& Vink, M.W. (2008). Projecting authenticity through advertising: consumer judgments of advertisers' claims. fournal of Advertising, 37(1), 5-15.

Breves, P.L., Liebers, N., Abt, M., \& Kunze, A. (2019). The perceived fit between Instagram influencers and the endorsed brand: how influencer-brand fit affects source credibility and persuasive effectiveness. fournal of Advertising Research, December, 440-454.

Brown, S., Kozinets, R.V., \& Sherry, Jr., J.F. (2003). Teaching old brands new tricks: retro branding and the revival of brand meaning. fournal of Marketing, 67(July), 19-33.

Chamberlain-Dilk, T. [@taychayy]. (2018, September 4). \#TransformationTuesday [Instagram photograph]. Retrieved from https://www.instagram.com/taychayy/?hl=en. 
Chamberlain-Dilk, T. [@taychayy]. (2019, August 4). Today i thought i would put some realness onto your timeline. [Instagram photograph]. Retrieved from https://www.instagram.com/taychayy/?hl=en.

Chamberlain-Dilk, T. [@taychayy]. (2019, November 1). **Swipe to the next pic, Jan $2018^{* *}$ [Instagram photograph]. Retrieved from https:// www.instagram.com/taychayy/?hl=en.

De Veirman, M., Cauberghe, V., \& Hudders, L. (2017). Marketing through Instagram influencers: the impact of number of followers and product divergence on brand attitude. International fournal of Advertising, 36(5), 798-828. https://doi.org/10.1080/02650487.2017.1348035

Fujita, M., Harrigan, P., \& Soutar, G. (2019). The strategic co-creation of content and student experiences in social media: an identity theories perspective. Qualitative Market Research: An International fournal, 22(1), 50-69.

Gannon, V., \& Prothero, A. (2016). Beauty blogger selfies as authenticating practices. European Journal of Management, 50(9/10), 1858-1878. https://doi.org/10.1108/EJM-07-2015-0510

Holt, D.B. (1997). Poststructuralist lifestyle analysis: conceptualizing the social patterning of consumption in postmodernity. Fournal of Consumer Research. 23(March), 326-350. https://doi.org/10.1086/209 487

Holt, D.B. (2002). Why do brands cause trouble? A dialectical theory of consumer culture and branding. Journal of Consumer Research, 29(June), 70-90. https://doi.org/10.1086/339922

Hughes, C., Swaminathan, V., \& Brooks, G. (2019). Driving brand engagement through online social influencers: an empirical investigation of sponsored blogging campaigns. fournal of Marketing, 83(5). 78-96. https://doi.org/10.1177/0022242919854374

Kavakci, E., \& Kraeplin, C.R. (2017). Religious beings in fashionable bodies: the online identity of hijabi social media personalities. Media, Culture \& Society, 39(6), 850-868.

Kerrigan, F., Brownlie, D., Hewer, P., \& Daza-LeTouze, C. (2011). 'Spinning' Warhol: celebrity brand theoretics and the logic of the celebrity brand. Journal of Marketing Management, 27(13/14), 1504-1524. 
Kozinets, R.V. (2020). Netnography: the essential guide to qualitative social media research. Sage.

Lowes, L. [@linnlowes]. (2019, July 8). Some day. [Instagram photograph]. Retrieved from https://www.instagram.com/linnlowes/?hl=en.

Lowes, L. [@linnlowes]. (2020, April 4).6 years cancer free. [Instagram photograph]. Retrieved from https://www.instagram.com/linnlowes/ ?hl=en.

Lowes, L. [@linnlowes]. (2020, February 1). Repost. [Instagram photograph]. Retrieved from https://www.instagram.com/linnlowes/ ?hl=en.

Preece, C. (2015). The authentic celebrity brand: unpacking Ai Weiwei's celebritised selves. fournal of Marketing Management, 31(5-6), 616-645. https://doi.org/10.1080/0267257X.2014.1000362

Psoriasis. (n.d.). Centers for Disease Control and Prevention. Retrieved April 30, 2020 from https://www.cdc.gov/psoriasis/index.htm https:// www.cdc.gov/psoriasis/index.htm

Shoenberger, H., Kim, E., \& Johnson, E.K. (2020). \#BeingReal about Instagram ad models: the effects of perceived authenticity. fournal of Advertising, 60(2), 197-207. https://doi.org/10.2501/JAR-2019-035.

Simmons, W. (n.d.). Whitney Simmons. Retrieved April 30, 2020 from https://whitneyysimmons.com/.

Simmons, W. [@whitneyysimmons]. (2019, May 31). It’s a beautiful day to be alive [Instagram photograph]. Retrieved from https://www. instagram.com/whitneyysimmons/?hl=en.

Simmons, W. [@whitneyysimmons]. (2020, January 7). I've spent the majority of the last 10 years hating my skin [Instagram photograph]. Retrieved from https://www.instagram.com/whitneyysimmons/?hl= en.

Simpson, L. [@laurensimpson]. (2020, February 16). 9am shredded at my photoshoot [Instagram photograph]. Retrieved from https://www. instagram.com/laurensimpson/?hl=en. 
Simpson, L. [@laurensimpson]. (2020, May 28). My body has gone through different phases [Instagram photograph]. Retrieved from https:// www.instagram.com/laurensimpson/?hl=en.

Simpson, L. [@laurensimpson]. (2020, May 31). Confidence [Instagram photograph]. Retrieved from https://www.instagram.com/ laurensimpson/?hl=en.

Thompson, C.J. (2004). Marketplace mythology and discourses of power. Journal of Consumer Research, 31(June), 162-180. https://doi.org/10 .1086/383432

Rose, R.L., \& Wood, S.L. (2005). Paradox and the consumption of authenticity through reality television. Fournal of Consumer Research, 32(2), 284-296. https://doi.org/10.1086/432238

Xiao, M., Wang, R., \& Chan-Olmsted, S. (2018). Factors affecting YouTube influencer marketing credibility: a heuristic-systematic model. fournal of Media Business Studies, 15(3), 188-213.

\section{Citation Information}

Foos, Adrienne E. "Adversity as Authenticity: How Influencers Use Personal Struggles to Build their Brands.” The BRC Academy fournal of Business 11, no. 1 (2021): 121-145. https://dx.doi.org/10.15239/ j.brcacadjb.2021.11.01.ja05

\section{Content Analysis Samples}

Screenshots of content analyzed are available from the author for professors who wish to understand the method and process in detail. 